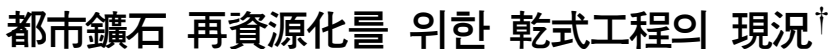

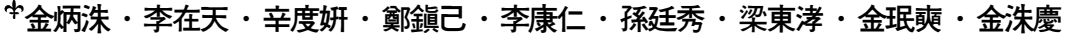 \\ 韓國地質資源研究院 鑛物資源研究本部 稀有資源研究center 都市鑛山team
}

\section{Current Status of Pyrometallurgical Process for the Reclamation of Urban Ore ${ }^{\dagger}$}

*Byung-Su Kim, Jaechun Lee, Doyeoun Shin, Jin-Ki Jeoung, Kang-In Rhee, Jeongsoo Sohn, Donghyo Yang, Min-Seuk Kim and Soo-Kyung Kim

Minerals and Materials Processing Division, Urban Mine Research Team, Korea Institute of Geoscience \& Mineral Resources(KIGAM), Yuseong-ku, Daejeon 305-350, Korea

\section{요 약}

유한자원의 순환활용과 환경보전 관점에서 도시광석으로부터 산업원료로 재사용될 수 있는 금, 은, 팔라듐 및 구리, 주석, 니켈, 코발트, 리튬 등 유용금속의 회수는 매우 중요하다. 현재까지 도시광석으로부터 유용금속을 회수하기 위한 많은 공정이 개발되었으 며, 그 중 일부는 상업적으로 가동되고 있다. 본 논문에서는 문헌을 통하여 조사된 도시광석으로부터 산업원료로 사용되는 유용금 속을 재생하기 위하여 개발된 중요한 건식공정들을 간략히 소개하고자 한다.

주제어 : 순환활용, 도시광석, 유용금속, 건식공정

\begin{abstract}
In the points of the environmental conservation and the recirculating utilization of limited resources, it is very important to recover valuable metals like $\mathrm{Au}, \mathrm{Ag}, \mathrm{Pd}, \mathrm{Cu}, \mathrm{Sn}, \mathrm{Ni}, \mathrm{Co}$, and $\mathrm{Li}$ used as industrial raw materials from urban ores. From now, many processes have been developed for recovering the valuable metals contained in urban ores and some of them have been operated commercially. In the paper, pyrometallurgical processes developed for reclaiming valuable metals from urban ores will be briefly introduced.
\end{abstract}

Key words : reusing, urban mine, valuable metal, pyrometallurgical process

\section{1. 서 론}

첨단제품에 대한 수요 증가와 중국의 자원무기화 움 직임 등을 배경으로 전 세계적으로 희유금속에 대한 관 심이 높아지고 있다. 이로 인해 산업의 비타민으로 비 유되고 있는 희유금속을 전량 수입에 의존하는 국내에 서는 자연광석이 아닌 도시광석으로부터 희유금속을 회 수하여 재자원화 하고자 하는데 많은 관심이 대두되고 있는 실정이다. 도시광석은 크게 폐휴대폰, 폐컴퓨터, 폐

\footnotetext{
†2012년 2월 6일 접수,

2012년 3월 2일 1차수정

2012년 3월 14일 수리

*E-mail: bskim@kigam.re.kr
}

텔레비젼, 폐건전지 등 사용 후 버려지는 폐전기전자기 기(생활-도시광석)와 폐촉매, 초경스크랩, 슬래그 등 산 업생산 공정에서 배출되는 부산물(공정-도시광석)로 나 눌 수 있으며, 이와 같은 각종 도시광석들에는 많은 종 류의 유용금속이 함유되어 있다. 특히, 생활-도시광석에 는 종류 및 제조시기에 따라서 다르지만 금, 은, 팔라듐 및 구리, 주석, 니켈, 코발트, 리튬 등 유용금속들이 상 당량 함유되어 있는 것으로 보고되고 있다. ${ }^{1-4)}$

현재 유렵, 미국, 일본 등 선진국과 국내에서는 크게 건식공정과 습식공정을 활용하여 도시광석(urban mine) 으로부터 금, 은, 팔라듐 및 구리 등의 유용금속을 회수 하여 금속 자원의 재자원화뿐만 아니라 환경오염 문제 
등을 해결하고 있다. 특히, 건식공정을 이용하여 도시광 석으로부터 유용금속을 회수하기위한 많은 상업적인 플 랜트가 가동 중에 있다. 이와 같이 건식공정이 도시광 석으로부터 유용금속을 회수하기 위하여 주로 사용되는 중요한 이유는 발생원과 제조시기에 따라서 구성성분이 달라지는 도시광석을 선별공정을 최소화 하여 처리가 가능하기 때문이다. 그러나 건식공정의 특성상 다양한 도시광석을 동시에 처리하기에는 조업이 곤란하다는 단 점이 있다. 반면에 도시광석으로부터 유용금속을 회수 하기 위한 습식공정은 기술적 난이도가 높고 환경적으 로 불리한 선별공정이 반드시 필요할 뿐만 아니라 이차 폐기물인 대량의 슬러지와 폐수를 배출하는 환경적인 문제점이 있어 제한적으로 가동되고 있는 상황이다. 이 와 같은 관점에서 이차 폐기물발생 저감 기술과 대량 처리가 가능한 효율적이면서 환경친화적인 도시광석의 재자원화 공정 기술개발에 대한 관심이 최근에 크게 대 두되고 있는 실정이다.

본 논문에서는 향후 도시광석의 재자원화 기술개발을 위해 생활-도시광석인 폐휴대폰, 폐컴퓨터 등 각종 정 보기기 등으로부터 배출되는 폐전기전자스크랩과 폐건 전지 그리고 공정-도시광석인 폐촉매와 초경합금 스크 랩으로부터 유용금속 회수를 위하여 개발된 건식공정 기술들을 간략히 소개하고자 한다. 따라서 본 논문이 향 후 도시광석의 재자원화 기술개발에 일조가 되었으면 한다.

\section{2. 폐전기전자스크랩 처리기술 현황}

현재 폐컴퓨터, 폐휴대폰 및 폐텔레비젼 등으로부터 배출되는 폐전기전자스크랩(WEEE, waste electrical and electronic equipment)으로부터 $\mathrm{Au}, \mathrm{Ag}$ 및 $\mathrm{Cu}$ 등 의 유용금속을 회수하는 건식공정은 기존 비철제련로를 활용하는 방법과 함비철 부산물을 처리하는 용융로를 활용하는 방법 두 가지로 크게 나눌 수 있다. 국내에서 는 LS-Nikko와 고려아연에서 납과 구리 제련공정을 이 용한 기존 제련로를 활용하는 방법으로 WEEE로부터 유용금속을 일부 회수하고 있는 상태이다. 반면에, 국외 에서는 벨기에의 Umicore와 일본의 Dowa 등에서는 함 비철 부산물을 처리하는 용융로를 스웨덴의 Rönnskår 에서는 납 용련공정(Kaldo 공정)을 이용한 기존 비철제 련로를 활용하는 공법으로, 캐나다의 Noranda에서는 구 리 용련공정을 이용한 구리 제련로를 활용하는 공법으 로 $\mathrm{WEEE}$ 로부터 유용금속을 회수하고 있는 것으로 알
려지고 있다. 또한, 스웨덴의 Rönnskär 에서는 함비철 부산물을 처리하는 용융로(zinc fuming furnace)를 활용 하여 WEEE로부터 유용금속을 회수하고자 연구를 시도 하고 있는 상태이다. 그러나 기존 비철제련로를 활용하 는 방법의 경우 WEEE의 투입량이 광석대비 $1 \%$ 미만이 며, 또한 함비철 부산물을 처리하는 용융로를 활용하는 방법의 경우도 기존 비철제련로를 할용하는 방법보다는 $\mathrm{WEEE}$ 의 투입량이 많으나 상대적으로 소량인 것으로 알려지고 있다. ${ }^{5,6)}$

\section{1. 납 제련공정 활용공정}

납 제련공정을 이용한 $\mathrm{WEEE}$ 로부터 귀금속과 구리의 회수는 귀금속을 납에 포집하여 회수하고, 구리를 부산물 인 구리 드로스(copper dross)와 구리 스파이스(copper speiss)로 회수한다. 즉, 고려아연의 QSL 공정과 Rönnskår 의 Kaldo 공정에서 납 제련로에 납정광과 함께 WEEE를 장입하여 산화납 $(\mathrm{PbO})$ 을 용융환원하며 동시에 $\mathrm{WEEE}$ 에 함유된 귀금속을 용융 납에 농축 분리 회수하고, WEEE 에 함유된 구리를 납 제련공정의 건식정련공정에서 발생 되는 copper dross와 납 제련공정의 슬래그의 fuming 공정에 의하여 발생되는 copper speiss로 분리 회수 하 는 것이다. 이 후 용융 납에 농축된 귀금속은 전해정련 과정 등을 통하여 분리되고 정제과정을 통하여 각기 고 순도의 귀금속으로 회수된다. 그리고 copper dross와 copper speiss는 구리 제련소에 보내어져 고순도의 구리 로 회수된다. 현재 납 제련공정에서 $\mathrm{WEEE}$ 의 장입량은 납 정광 대비 $0.4-0.7 \%$ 정도로 투입되고 있으나 WEEE 의 장입량이 증대됨에 따라서 가스 발생량의 증가로 황 산 제조 공정의 문제와 배출 가스의 재처리를 해야 하는 단점이 있다. Fig. 1은 연속납제련공정인 QSL제련로의 개략도를 각각 나타낸 것이다. ${ }^{7)}$

\section{2. 구리 제련공정 활용공정}

일반적으로 구리 제련공정에서 $\mathrm{WEEE}$ 로부터 금, 은, 팔라듐 및 구리 회수는 매트제련 공정과 전로공정에서 이루어진다. 매트제련 공정에서는 구리 매트를 전로공 정에서는 용융 구리를 귀금속과 구리의 포집금속으로 활용하는 것이다. 매트제련 공정에서는 구리정광과 함 께 $\mathrm{WEEE}$ 를 매트제련로에 장입하여 동광석 $\left(\mathrm{CuFeS}_{2}\right)$ 과 $\mathrm{O}_{2}(\mathrm{~g})$ 간에 일어나는 격렬한 산화반응을 이용하여 $\mathrm{Cu}_{2} \mathrm{~S}$ 를 용융하면서 동시에 $\mathrm{WEEE}$ 에 함유된 귀금속과 유가 금속을 매트에 농축 분리 회수한다. 전로공정에서는 매 트로부터 조동을 제조하기 위하여 산소 주입에 의한 탈 
황 및 탈철을 하는 과정에서 발생하는 과잉의 열을 냉 각하기 위하여 냉재 대체용으로 WEEE를 장입함으로서 동시에 WEEE에 함유된 금, 은, 팔라듐 및 구리 등을 조동에 농축 분리 회수한다. 이후 금, 은, 팔라듐 등은 전해정련과정을 통하여 조동으로부터 분리 회수된다. 분 리 회수된 귀금속 농축물은 일련의 정련과정을 통하여 각기 고순도의 귀금속으로 회수된다. 현재 구리 제련공 정 활용공정에서 $\mathrm{WEEE}$ 의 장입량은 구리 정광 장입량 대비 $0.6 \%$ 정도 그리고 매트 장입량 대비 $0.1 \%$ 정도 로 투입되고 있다. 이 공법은 납 제련 공법과 같이 초기 투자비용을 들이지 않고 기존 설비를 활용하여 WEEE로 부터 유용금속을 회수할 수 있다는 장점이 있으나, 마찬 가지로 $\mathrm{WEEE}$ 의 장입량이 증대됨에 따라서 구리 제련 공정에서 부산물로 회수되는 황산 공정에 많은 문제점 을 야기하고, 배출 가스의 재처리를 해야 하는 단점이 있다. Fig. 2는 Mistubishi 구리 제련법의 개략적인 공 정도를 나타낸 것이다. ${ }^{8}$

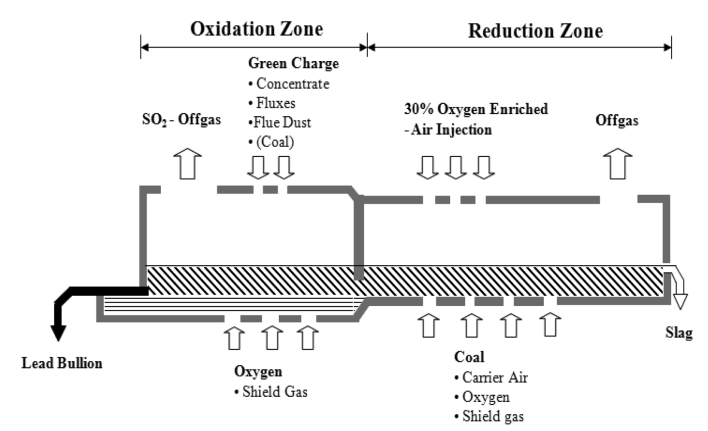

Fig. 1. Schematic diagram of QSL lead smelter ${ }^{7}$.

\section{3. 함비철 부산물 처리 용융로 활용공정}

이 공정은 비철제련 공정에서 발생되는 구리 드로스 (copper dross), 구리 스파이스(copper speiss) 및 습식 공정에서 배출되는 각종 잔사 그리고 슬래그 등을 재처 리하여 유용금속을 회수하는 용융로에 WEEE를 적당량 투입하여 유용금속을 회수하는 공정이다. 대표적인 공 정은 밸기에의 Umicore에서 상업화되고 있는 IsaSmelt 로를 활용하는 공법이다.9) 이 공법에 의한 WEEE에 함 유된 $\mathrm{Au}, \mathrm{Ag}, \mathrm{Cu}$ 등의 유용금속 회수 메카니즘은 앞 에서 설명한 구리 전로공정과 매우 유사하다.

\section{3. 폐건전지 처리기술 현황}

폐건전지에는 크게 납축전지, 니켈-카드뮴전지, 망간

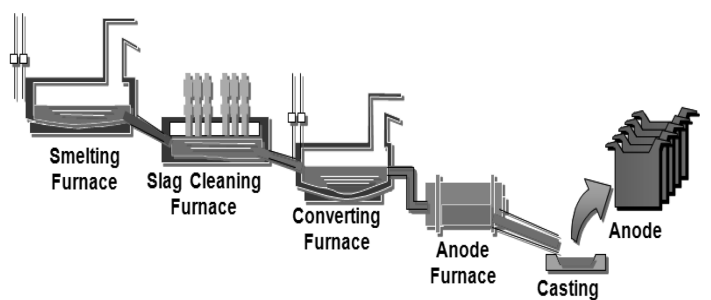

Fig. 2. Mitsbish copper smelter flow diagram ${ }^{8}$.

전지, 알칼리 망간전지 및 리튬전지 등이 있으며 일반 적으로 납축전지는 용융법으로, 니켈-카드뭄전지는 증류 법으로 재자원화 되고 있다. 또한, 최근에 국내에서 망 간전지와 알칼리 망간전지 그리고 리튬전지를 습식법에 의하여 재자원화하는 상업화 공정이 가동 중에 있다. 한 편, 밸기에 Umicore사에서는 리튬전지를 코발트 제련로 에 투입하여 코발트를 재자원화하는 상업화된 공정을 가동 중에 있는 것으로 알려지고 있다. ${ }^{9)}$

\section{1. 폐납축전지의 재자원화 공정}

폐납축전지의 처리기술은 기존 납제련로 활용법, 반 사로법(reverberatory furnace), 로터리 킬른 법(rotary kiln) 그리고 큐폴라법(cupola) 등이 있으며, 국내에서는 주로 기존 납제련로 활용법과 큐폴라 법을 채용하고 있 다. 기존 납제련로 활용법은 폐납축전지를 해체하여 황 산과 케이스인 플라스틱을 제거한 후 Fig. 1 의 납제련 로에 투입하여 제련하는 공정이다. 큐폴라법은 폐납축 전지를 해체하여 황산과 케이스인 플라스틱을 제거한 후, 열원 및 환원제로 코크스와 그리고 용융제로 규석, 석회석 및 큐폴라 슬래그를 함께 사용하여 제련하는 방 법이다. ${ }^{10)}$

\section{2. 니켈 - 카드뮴 재자원화 공정}

니켈-카드뮴 폐전지 재활용은 폐전지 내부를 노출시 킨 뒤 감압 증류로에서 $900^{\circ} \mathrm{C}$ 정도로 증류하여 카드뭄 을 증발시켜 냉각하여 괴로 회수하고 증류잔사인 니켈, 철 성분은 페로니켈의 원료로 재자원화하는 공정이다. ${ }^{11)}$ 현재 이러한 건식법만이 일본, 미국 그리고 유럽에서 상 용화되고 있다.

\section{4. 폐촉매 처리기술 현황}

귀금속을 함유하고 있는 폐촉매로는 크게 정유공장에 서 발생하는 석유화학 폐촉매와 자동차 배기가스 정화 
용 폐촉매 등이 있다. 석유화학 폐촉매로는 백금 폐촉 매와 팔라듐 폐촉매가 있으며, 자동차 폐촉매로는 팔 라듐, 백금-로듐, 팔라듐-로듐, 백금-팔라듬-로듐계 등 이 있다. 이와 같은 폐촉매에는 상당량의 백금족 금 속이 함유되어 있어, 오래전부터 고온추출 공정과 습 식추출 공정 등으로 백금족 금속을 분리 회수하고 있 다. 한편, 폐촉매에 함유된 백금족 금속을 선택적으로 염화시켜 휘발성 백금족 금속 화합물을 형성하고 이 를 냉각 영역내에서 응축시켜 분리 회수하는 기상휘 발 공정이 개발되었으나 아직까지 상업화는 이루어지 지 않고 있다.

\section{1. 고온추출 공정}

고온추출 공정은 폐촉매와 용제(flux) 그리고 금속을 혼합하여 용융하여 폐촉매에 함유된 백금족 금속을 금속 상에 포집하여 분리 회수하는 공정이다. 이와 같은 공정 에서 얻어진 백금족 금속이 농축된 금속상은 추가적인 공정을 통하여 고순도의 백금족 금속으로 회수 된다. 고 온추출 공정에서 사용되는 금속은 보통 포집금속이라 부르며, 포집금속은 액상에서의 백금족 금속의 고용성 이 높고, 슬래그로의 금속 손실이 적고 융점이 낮을수 록 좋다. 일반적으로 포집금속으로는 철, 구리, 구리메 트, 니켈, 납 등이 사용되고 있다. 현재, 대표적인 고온 추출 공정에 의한 상업화된 공정은 일본 $\mathrm{PGM}$ (주)의 로즈 프로세스와 밸기에 Umicore의 IsaSmelt 로를 이 용하는 공정이 있으며, Fig. 3에 일본 $\mathrm{PGM}$ (주)의 로즈 프로세스의 공정 흐름도를 나타냈다. ${ }^{2)}$

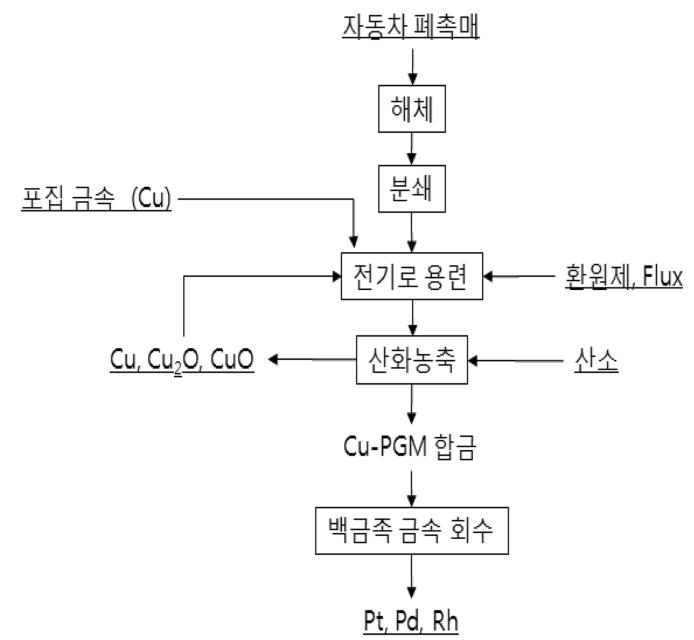

Fig. 3. Flow sheet of Rose of PGM Co. Ltd. in Japan ${ }^{12)}$.

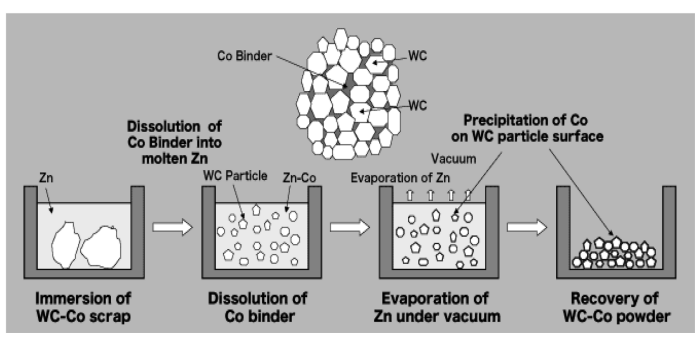

Fig. 4. Flow sheet of Zinc process of Kohsei Co. Ltd. in Japan. ${ }^{13)}$

\section{5. 초경합금 스크랩 처리기술 현황}

일반적으로 초경합금 스크랩은 WC-Co계 초경합금 스크랩을 말한다. 초경합금 스크랩의 재자원화를 위한 방법에는 텅스텐 카바이드와 점결제인 코발트를 회수하 는 건식공정인 직접재활용법과 용융법 그리고 점결제를 회수하는 습식법인 반직접재활용법과 텅스텐과 코발트 모두를 회수하는 습식법으로 대별될 수 있다. 이 중 대 표적인 상업화된 건식공정에는 아연처리 공정이 있다.

\section{1. 아연처리 공정}

Fig. 4는 아연처리 공정도를 도식화한 것이다. ${ }^{13)}$ 아연 처리 공정은 코발트와 아연의 강한 결합력과 아연의 휘 발특성을 이용하여 초경합금 스크랩을 재자원화하는 공 정으로써, 먼저 초경합금 스크랩과 아연을 도가니에 장 입하여 불활성분위기에서 $700 \sim 1,000^{\circ} \mathrm{C}$ 로 가열하여 코 발트를 아연에 용출시켜 분리한 후, 감압하에서 재차 가 열 하여 아연을 휘발분리시켜 텅스텐 카바이드와 코발 트를 분말상태로 회수하는 공정이다.

이 밖에 초경합금 스크랩의 재자원화 공정에는 bloating/crushing 공정과 산화환원 공정이 있다. bloating/ crushing 공정은 초경합금 스크랩을 불활성분위기에서 $1800^{\circ} \mathrm{C}$ 로 열처리한 후 급냉하여 취화시킨 후 분쇄하여 텅스텐카바이드 분말을 얻는 방법이다. 그리고 산화환 원 공정은 초경합금 스크랩을 산화성분위기에서 $800^{\circ} \mathrm{C}$ 로 가열하여 산화시킨 후 분쇄하여 초경합금 스크랩을 분말화 한 다음, $900 \sim 1,000^{\circ} \mathrm{C}$ 에서 수소환원하여 텅스텐 분말을 얻는 방법이다.

\section{6. 결 론}

본 논문에서는 생활-도시광석인 폐휴대폰, 폐컴퓨터 등 각종 폐정보기기 등으로부터 배출되는 폐전기전자스 
크랩과 각종 모빌 전자장비로부터 배출되는 폐건전지 그리고 공정-도시광석인 석유화학 폐촉매 및 자동차 폐 촉매와 특수공구강 제조공정에서 배출되는 초경합금 스 크랩으로부터 유용금속 회수를 위하여 상업화된 건식공 정 위주로 간략히 소개하였다. 이상의 조사 결과를 바 탕으로 향후 각종 도시광석의 재자원화를 위한 공정 개 발은 이차 폐기물발생 저감 기술과 대량 처리가 가능한 효율적이면서 환경친화적인 기술에 집중될 것으로 예측 된다.

한편, 도시광산 산업은 유럽, 일본, 중국과의 경쟁이 필연적이나 지역적으로 멀리 떨어져 있는 유럽의 영향 보다는 일본과 중국과는 직접적인 경쟁을 벌일 수밖에 없다. 기술을 무기화하고 있는 일본은 DOWA를 중심으 로 도시광산 산업 시스템 구축을 이루어가고 있다. 또 한 자원을 무기화하고 있는 중국은 전국에 도시광산 산 업 시범기지를 건설하여 도시광석의 자원화를 주도하려 는 정책을 펴고 있다. 따라서 국내 도시광산 산업의 현 황을 철저히 분석하여 대처하는 길이 positioning trap 에서 벗어나 도시광산 산업의 활성화로 관련 산업의 경 쟁력을 키워나가야 할 것으로 사료된다.

\section{사 사}

본 연구는 한국지질자원연구원 기본사업인 ‘희유금속 [백금족 (Pt, $\mathrm{Pd}, \mathrm{Rh}), \mathrm{Co}, \mathrm{Ni}, \mathrm{Sn}$ ] 재자원화를 위한 하이브리드 공정 개발 (12-3111-2)' 과제의 일환으로 수 행되었습니다.

\section{참고논문}

1. UNEP report, 2004: E-waste, the hidden side of IT

\section{金 炳 洙}

- 현재 한국지질자원연구원 광물자원연구본부 책임연구원 - 당 학회지 제 13 권 1 호 참조 equipment manufacture and use, http://www.grid.unep.ch/ product/publication/download/ew_ewaste .en.pdf

2. Jae-chun Lee, Jin-ki Jeong, Jung-il Yang, Hun-Sang Chung, 1998: Technology for Recovering Valuable Metals from Printed Circuit Boards (PCBs) of the Used Personal Computer, J of Korean Inst. of Resources Recycling, 7(3), pp.58-66.

3. Elaine. Y. L. Sun, 1991: The Recovery of Metals from Electric Scrap, JOM, 43(4), pp.53-61.

4. J. E. Hoffmann, 1992: Recovering Precious Metals from Electric Scrap, JOM, 44(7), pp.43-48.

5. Private communication Korea-Zinc Incorporation, Uljin-gun, Ulsan, Korea, September, 2011.

6. Private communication LS-Nikko Copper Incorporation, Uljin-gun, Ulsan, Korea, November, 2011.

7. Y. Lee, N. Moon, C. Choi, 1995: Behavior of Lead and Zinc in Non-ferrous Bath Smelting, Proceedings of the 2nd International symposium on quality in non-ferrous pyrometallurgy, M. A. Kozlowski, R. W. McBean and S. A. Argyropoulos(Ed.), Vancouver, Canada, pp. 358.

8. Technical information of Mitsubishi continuous process at LS-Nikko Copper Smelter: http://www.lsnikko.com/tech/ tech_jea_lg.aspx

9. C. Hagelken, 2006: Recycling of Electronic Scrap at Umicore Precious Metals Refining, Acta Metallurgica Slovaca, 12, pp.111-120.

10. (주) 중일 폐납축전지 재활용기술 정보: http://www.joongil.com/process $01 . h t m$

11. 자원재활용사업단 (사)한국자원리싸이클링학회, 2009: 리 싸이클링백서, p. 250.

12. 자원재활용사업단 (사)한국자원리싸이클링학회, 2009: 리 싸이클링백서, p. 286.

13. Technical information for the recycling of WC-Co Scrap at Kohsei Co. Ltd. in Japan: http://www.kohsei.co.jp/english/ business/kitakyushu.html

\section{李 在 天}

- 현재 한국지질자원연구원 광물자원연구본부 책임연구원 - 당 학회지 제 10 권 6 호 참조 


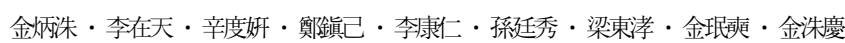

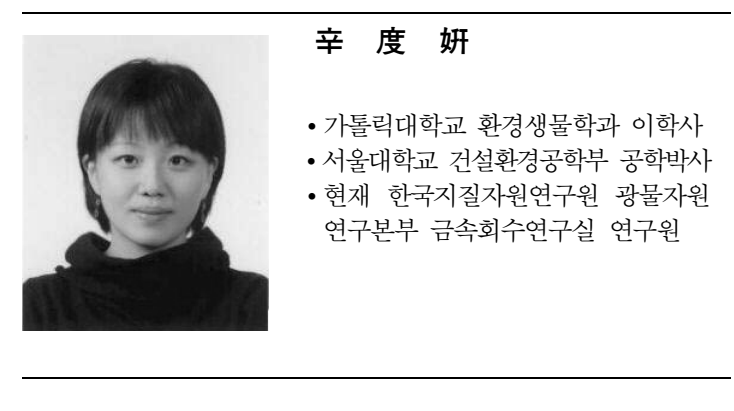

李 康 仁

• 현재 한국지질자원연구원 광물자원연구본부 책임연구원 - 당 학회지 제 8 권 5 호 참조

梁 東 涍

- 현재 한국지질자원연구원 광물자원연구본부 선임연구원 - 당 학회지 제 8 권 5 호 참조

金 珢 奤

- 현재 한국지질자원연구원 광물자원연구본부 책임연구원

• 당 학회지 제 13 권 5 호 참조

J. of Korean Inst. Resources Recycling Vol. 21, No. 2, 2012

\section{鄭 鎭 己}

- 현재 한국지질자원연구원 광물자원연구본부 책임연구원 - 당 학회지 제 15 권 5 호 참조

孫廷 秀

- 현재 한국지질자원연구원 광물자원연구본부 책임연구원 •당 학회지 제 12 권 1 호 참조

金 洙 慶

- 현재 한국지질자원연구원 광물자원연구본부 선임연구원 - 당 학회지 제 19 권 4 호 참조 